\title{
Algo para lembrar os segredos dos dias estranhos: a cosmovisão de H.P. Lovecraft em Stranger Things
}

\author{
Lúcio Reis Filho \\ Universidade Anhembi Morumbi
}

\section{Resumo}

Coisas estranhas acontecem em Hawkins, Indiana. Em 1983, fenômenos sobrenaturais começam a assolar a pacata cidade do médio oeste americano depois que uma agência governamental de fins escusos abre um portal para outra dimensão, libertando os horrores que lá habitam. Esta é a premissa de Stranger Things (2016-17), série original da Netflix, criada pelos irmãos Duffer. Todavia, sabemos de qual dimensão esses fenômenos vêm: das páginas de Stephen King, dos filmes de Steven Spielberg e Ridley Scott; do tabuleiro de Dungeons \& Dragons. A despeito dos mais óbvios canais de intertextualidade, observaremos a influência mais relevante para a criação da atmosfera de horror da segunda temporada: a obra de H.P. Lovecraft, notadamente o conto A cor que caiu do espaço (1927) e os Mitos de Cthulhu. A inspiração em Lovecraft, declarada pelos criadores da série, transforma Hawkins em uma paisagem de horror, leva um dos protagonistas à beira da loucura e projeta a sombra mortal de uma abominação antiga.

\section{Palavras-chave}

Stranger Things; H.P. Lovecraft; A Cor que Caiu do Espaço; Mitos de Cthulhu.

\section{Lovecraft no subúrbio}

Na superfície, a série Stranger Things captura a forma pela qual os subúrbios americanos foram comumente representados no cinema nos anos de 1980. Em um nível mais profundo, porém, o grande sucesso da Netflix toca em antigos mitos do país. De acordo com Joshua Rothman (2016), sua ideia central - de que o insólito é mais estranho e, por consequência, mais assustador do que o estado de natureza - remontaria a 1927, ano em que foi publicado A Cor que Caiu do Espaço. Nesse conto de H.P. Lovecraft e na sua obra como um todo, os personagens exploram o desconhecido e descobrem que o horror é a norma. Em The King of Weird (1996), introdução à obra selecionada desse escritor, Joyce Carol Oates considera a mitologia criada por ele uma "inversão irônica da fé religiosa tradicional": 
Constitui o desenvolvimento elaborado e detalhado de uma fantasia recorrente de Lovecraft, de que toda uma civilização alienígena se esconde nos subterrâneos do mundo conhecido; (..) assim como a natureza tragicamente dividida da humanidade pode se esconder sob o verniz da civilização. (...) Nos Mitos de Cthulhu não há "deuses", apenas seres extraterrestres deslocados, os Grandes Anciões que viajaram para a Terra há muitos milhões de anos (...). Os seres humanos iludidos confundem os Grandes Anciões e seus descendentes com deuses, adorando-os por ignorância (OATES, 1996).

Para Oates, a idiossincrática fantasia de horror de Lovecraft é quintessencialmente americana - fruto da união da espiritualidade puritana com a estranheza da Nova Inglaterra - e pode ser rastreada até os séculos XVIII e XIX. Pela adição de elementos contemporâneos, de fin de siècle e das primeiras décadas do século XX, à atmosfera de medo espiritual do século XVIII, o escritor tocou em quatro temas que amedrontavam seus conterrâneos naquele momento histórico: os lugares selvagens, o demônio, a miscigenação e a evolução. Ao fazê-lo, criou um modelo de narrativa de horror permeada de alucinações, ocultismo e ciência que nos atrai ainda hoje (ROTHMAN, 2016). Nas últimas décadas, inúmeros filmes, livros, games e séries de televisão tentam atualizar essa fórmula lovecraftiana, enfatizando alguns de seus aspectos e minimizando outros. Exemplos bemsucedidos no cinema, como os clássicos do horror Alien (dir. Ridley Scott, 1979) e O Enigma de Outro Mundo (1982, dir. John Carpenter), valorizam a atmosfera, mais do que a ação.

De acordo com Michael Kelahan (2011, p. ix), os contos e noveletas de Lovecraft têm atraído diretores, roteiristas e atores, tanto de Hollywood como da cena independente de diversos países. Andy Black (1996), Andrew Migliore e John Strysik (2006), entre outros, atestam as inúmeras adaptações ou filmes inspirados em seu trabalho que surgiram na segunda metade do século XX. A transposição de Lovecraft para as telas remontaria aos anos de 1950 - em filmes que, embora não se tratem de adaptações per se, evocam um sentimento de estranheza, com uma verve sobrenatural carregada de medo cósmico; ${ }^{1}$ mas foi nos de 1970 e 1980 que o "cinema lovecraftiano" viveu seu momento mais fértil. A visão pessimista engendrada pelo escritor, somada aos medos arquetípicos da sociedade norte-americana, postos em sua obra, mostra-se atraente no momento em que o sonho da contracultura desvanecia e uma nova geração criava uma

$1 \quad$ Black sugere que a fonte de inspiração para as criaturas de O Monstro da Lagoa Negra (Creature from the Black Lagoon, dir. Jack Arnold, 1954) e O Monstro das Pedras Brancas (The Monster of Piedras Blancas, dir. Irwin Berwick, 1959) tenha sido "Dagon" (1917), um dos primeiros contos de Lovecraft. 
nova forma de fazer filmes. A emergência de Lovecraft ocorre em um contexto de crescente intertextualidade, quando, segundo Noël Carroll, elementos icônicos do horror remetiam seus adeptos às fontes literárias, estimulando o interesse por escritores desses gêneros e pela tradição que deles se originou (1999, p. 20). Os contos de Lovecraft passam a inspirar nomes do novo cinema independente, como Roger Corman e Daniel Haller, e autores como Stephen King, Ridley Scott, John Carpenter, Stuart Gordon e Clive Barker. Aspectos literários, estéticos e filosóficos de sua obra foram apropriados pelo cinema daquele período, notadamente pelas produções dos anos 1980, que mesclam horror e ficção científica.

Retomemos aqui a discussão sobre a tendência das produções audiovisuais contemporâneas de se voltarem para a década de 1980, tendência esta acentuada nos últimos anos e que evidencia a emergência do "retrô" como gênero na cultura pop. A narrativa de Stranger Things foi situada naquela década, cujas produções mais icônicas do horror são "em essência, Lovecraft no subúrbio: tomam fantasias paranoicas e sinistras inspiradas no passado colonial, puritano e racista dos Estados Unidos e as atenuam, fazendo com que se desenrolem em um contexto mais inocente" (ROTHMAN, 2016). Não obstante, o núcleo da história lovecraftiana permanece intacto. Diferentes filmes que inspiraram a série foram realizados por cineastas comprometidos, em algum nível, com adaptações do escritor. Além do supracitado Alien, uma postagem no fórum Reddit ${ }^{2}$ sugere a influência de "Do além" (1934), de Lovecraft, adaptado por Stuart Gordon, em 1986. O personagem central do conto se reúne com um velho amigo que afirma ter descoberto um mundo alheio à experiência humana. Ele presume que esse outro mundo tenha sempre estado lá, invisível e inacessível, até o momento em que desenvolve meios de desvelá-lo. Passa, então, a visualizar as criaturas estranhas e gelatinosas desse mundo alternativo. Entretanto, em uma virada surpreendente, o homem descobre que, se pode vê-las, as criaturas também o percebem; não fosse o bastante, elas têm a capacidade de caçar, capturar e até mesmo destruir o nosso mundo. $\mathrm{O}$ paralelo com a dimensão alternativa de Stranger Things, conhecida como "Mundo Invertido", ou com as monstruosidades biológicas gosmentas, não é acidental. Na série, a curiosidade ingênua e o otimismo científico levam os personagens a descobrir, nas palavras de Oates, "que toda uma civilização alienígena espreita nas profundezas do mundo conhecido" (1996, grifo meu). ${ }^{3}$

A inspiração em Lovecraft, admitida pelos próprios criadores de Stranger Things à Entertainment Weekly, ${ }^{4}$ tem gerado bastante discussão na internet e nas redes sociais. A despeito dos canais mais óbvios de intertextualidade (os filmes de horror e ficção científica dos anos de 1980), demonstrarei como a obra desse escritor - notadamente o conto A cor que caiu do espaço e alguns elementos dos

2 Dados de acordo com: https://www.reddit.com/r/StrangerThings/comments/5kykzw/the_influence_of _h_p_lovecrafts_from_beyond_on/

3 Oates utiliza a palavra "underside".

4 Dados de acordo com: http://ew.com/tv/2017/09/28/stranger-things-2-new-monster/ 
"Mitos de Cthulhu" - foi determinante para a criação da atmosfera horrífica da segunda temporada. Essa abordagem transforma Hawkins em locus horribilis, leva um dos protagonistas à beira da loucura e projeta a sombra mortal de uma abominação antiga. Além disso, reatualiza a mitologia lovecraftiana para o público moderno.

\section{A cor que caiu do espaço e outras coisas mais estranhas.}

No primeiro episódio (2.1 "Mad Max") da segunda temporada de Stranger Things, o delegado Jim Hopper (David Harbour), do Departamento de Polícia de Hawkins, conduz uma investigação na área rural da cidade, onde uma estranha doença matara a plantação de abóboras da Fazenda de Merill. Os frutos jazem podres pelo campo, com feridas purulentas na casca escurecida, atraindo um semnúmero de varejeiras. $\mathrm{O}$ dono da propriedade (Fenton Lawless) acusa o vizinho de ter envenenado as suas terras. No segundo episódio (2.2 "Trick or Treat, Freak"), o delegado interroga Eugene (Al Mitchell), o vizinho, sobre o caso das abóboras, mas o homem inverte o jogo e acusa Merill de ter envenenado a sua plantação. $\mathrm{O}$ ato seria um acerto de contas, pois Merill pensava que as suas terras haviam sido envenenadas primeiro. Eugene tem um álibi e afirma que, há tempos trabalhando nesse ramo, nunca vira nada parecido. "Nenhum de nós viu", diz ao delegado, reafirmando a suposição. "Merill não envenenou só a minha terra, foram muitas. Do Jack O’Dell, do Pete Trelling, do Rick Neary, dos Christensens. Todas as plantações, mortas".

O fazendeiro leva o delegado à sua propriedade. A doença está se espalhando como a praga, as terras de cultivo se tornaram cinzentas e sem vida, como se tivessem sido queimadas. Muco viscoso brota do tronco das árvores. O fedor é insuportável. Hopper ordena que os oficiais descubram até onde vai a podridão: "Marquem tudo, pode ser veneno". Os policiais começam a demarcar a área afetada com bandeirinhas de sinalização. Passam o dia inteiro fazendo isso. Quando Hopper observa o campo à noite, impressionado com a extensão de terra morta, toda a área está coberta de névoa. No terceiro episódio (2.3 “The Pollywog"), os cientistas de uma base governamental instalada nos arredores da cidade coletam uma abóbora apodrecida e amostras do solo. Toda a área isolada pelos agentes do governo está morta e infértil. O caso de Hawkins e as imagens da terra arrasada evocam os "dias estranhos" e o "descampado maldito" de A cor que caiu do espaço (1927), considerada por S.T. Joshi "o primeiro dos grandes contos de Lovecraft a efetuar a união entre horror e ficção científica, que mais tarde tornarse-ia marca registrada de seu trabalho" (2013, p. 671).

\footnotetext{
5 Nome atribuído a um conjunto de histórias que, além de serem interligadas e possuírem cenários e personagens em comum, pressupõem a existência de um panteão de seres alienígenas que governaram a Terra em tempos remotos, antes da humanidade; essas deidades esperam retornar para a Terra e o seu retorno culminará na aniquilação da nossa espécie.
} 


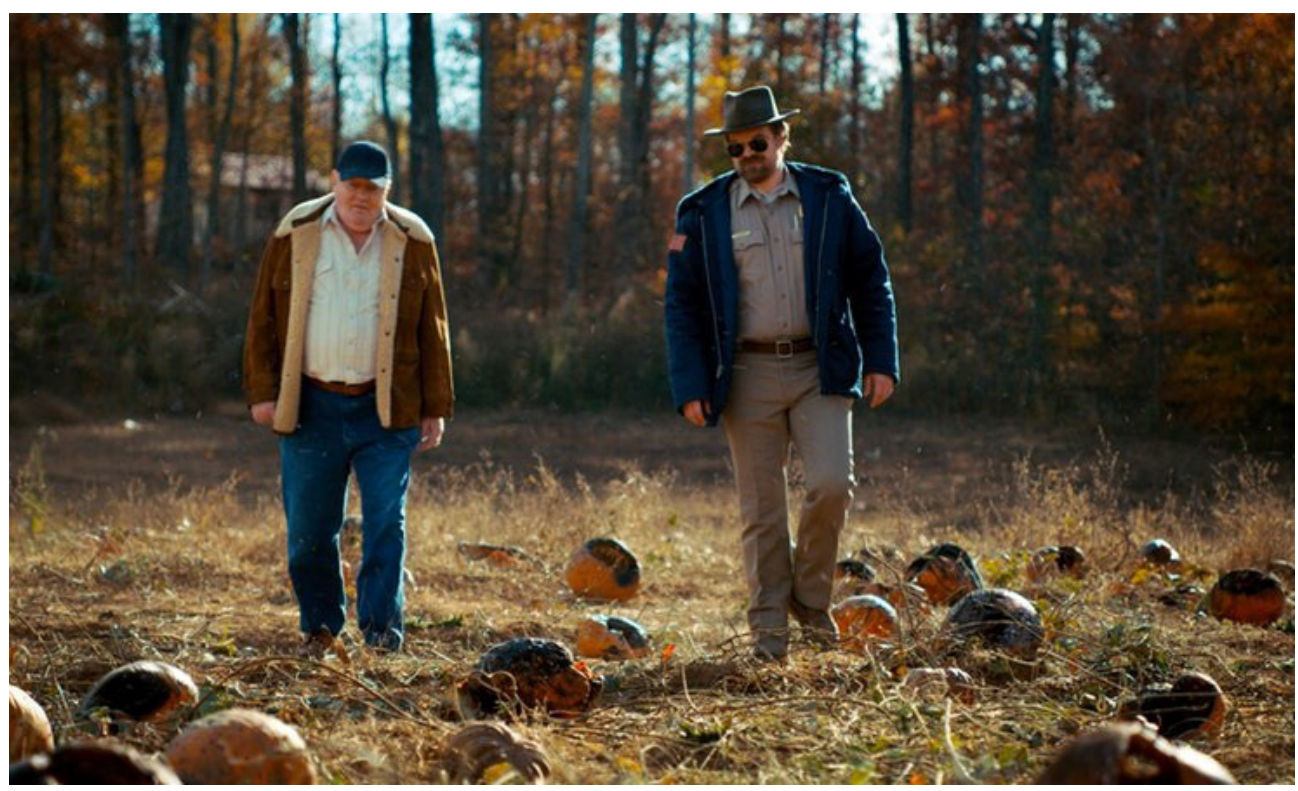

Figura 1 - O Delegado Jim Hopper (à direita) investiga uma das plantações tomadas pela misteriosa praga.

Fonte: Netflix

História favorita de Lovecraft, $A$ cor que caiu do espaço foi definida por ele como um "estudo de atmosfera" (citado por JOSHI, 2013, p. 671), o que se deve à criação de uma paisagem de horror inexplicável no coração da Nova Inglaterra. Logo nos primeiros parágrafos, o narrador faz uma descrição vívida da área rural:

Nos espaços abertos, e em especial ao longo da antiga estrada, pequenas fazendas empoleiravam-se nas encostas; às vezes com todas as construções ainda de pé, às vezes com apenas uma ou duas remanescentes e às vezes com apenas uma chaminé solitária ou um pequeno porão meio soterrado. As ervas daninhas e os espinheiros reinavam, e coisas furtivas e selvagens farfalhavam em meio à vegetação rasteira. Uma névoa de inquietude e opressão pairava sobre tudo; um toque irreal e grotesco, como se algum elemento vital de perspectiva ou de chiaroscuro não estivesse correto. Não me admirei ao saber que os estrangeiros não haviam ficado por lá, pois aquela não era uma região propícia ao sono. O cenário lembrava uma paisagem de Salvator 
Rosa; uma xilogravura proibida em uma história de terror (LOVECRAFT, 2011, p. 21).

Mas, segundo o relato, nenhuma dessas características era tão ruim quanto o "descampado maldito" com que se deparou ao descer até as profundezas de um vale. À primeira vista, cogitou ser aquilo o resultado de um incêndio, embora fosse incapaz de compreender o porquê de nada novo ter brotado "naqueles cinco acres de desolação cinzenta que se estendiam sob o céu como uma grande mancha corroída por ácido em meio aos campos e bosques" (LOVECRAFT, 2011, p. 21). Conforme observa, "Não havia vegetação de nenhum tipo em toda aquela extensão de terra - apenas um fino pó cinzento que nenhum vento parecia espalhar. As árvores próximas eram doentes e retorcidas, e muitos troncos mortos apodreciam ao redor" (LOVECRAFT, 2011, p. 22).

Em sua exploração, o narrador encontra o velho Ammi Pierce, fazendeiro local que guarda memórias das "coisas estranhas" ocorridas na região. Ammi oferece um relato detalhado dos "dias estranhos". Segundo ele, tudo começou com a queda de um meteorito, em 1882. Naquele ano, à época da colheita, as peras e as maçãs amadureciam lentamente, e Nahum Gardner, outro fazendeiro local, regozijou-se com a impressão de que seus pomares prosperavam como nunca antes. As frutas cresciam extraordinariamente e ganhavam um brilho inusitado. Porém, a maturação trouxe uma decepção. Apesar da aparência deslumbrante, nenhuma das frutas servia para comer, nem os melões e os tomates, pois desenvolveram um amargor doentio. Nahum logo percebeu que toda a sua colheita estava perdida. Conectando os eventos, o fazendeiro concluiu que o meteorito envenenara o solo (LOVECRAFT, 2011, pp. 30-1).

Nas matas ao longo da estrada, moradores locais começaram a notar a coloração estranha e o tamanho descomunal das aráceas que brotavam da lama. Suas formas eram monstruosas e os cavalos bufavam com o odor sem precedentes. Certo dia, "muitas pessoas foram até lá para ver o fenômeno fora do normal, e todos concordaram que plantas como aquelas jamais cresceram em um mundo saudável" (LOVECRAFT, 2011, p. 33). Não demorou a correr de boca em boca que as terras de Nahum haviam sido envenenadas. Pouco depois disso, uma alteração anômala na grama e nas folhas tornou-se visível a olho nu. Toda a vegetação ficou cinzenta e quebradiça. A verdura e até mesmo as flores, cujos matizes haviam se tornado brilhantes, ganharam uma coloração cinza, assim como as frutas, agora anãs e insípidas. Meses mais tarde, toda a vegetação se decompôs em um pó cinzento e Nahum temia que as árvores pudessem morrer antes que o veneno fosse debelado. Sem demora, o colapso, as cinzas e a desintegração avançavam para a casa de fazenda.

Ammi decidiu averiguar a fazenda de Gardner, e descobriu que toda a família estava morta. Após notificar as autoridades, levou três oficiais à fazenda tomada pela praga, acompanhado do investigador forense, do médico legista e do 
veterinário que tratara os animais doentes. Não fosse terrível o bastante o aspecto da terra, "lugar maldito" em sua desolação cinzenta, havia coisas se desfazendo que superavam todos os limites. Ninguém pôde fixar os olhos sobre elas, e até mesmo o legista admitiu que restara pouca coisa a ser examinada. $\mathrm{O}$ avanço das cinzas deixou todos atônitos. "Essa coisa se espalha por toda a matéria orgânica ao redor”, murmurou o médico legista (2011, p. 57). Os homens se perguntavam por que tudo estava cinza e quebradiço, incapazes de encontrar resposta racional. Em retrospecto, o narrador conclui que “(...) os segredos daqueles dias estranhos serão um só com os segredos das profundezas; um só com a sabedoria oculta do velho oceano e com todos os mistérios da Terra primitiva" (LOVECRAFT, 2011, p. 20).

\section{O hábitat das ocorrências monstruosas}

Em A cor que caiu do espaço nota-se um recurso comumente aplicado por Lovecraft em seus personagens: é o narrador protagonista quem descreve, em primeira pessoa, o ambiente que o cerca e o fenômeno anômalo que testemunha (podendo relatar, também, o seu estado mental flutuante); por consequência, o racionalismo sucumbe em face do desconhecido (JOSHI, 2013, pp. 115; 116). Logo, temos uma prosa quase inteiramente dedicada à exposição e à narração, com ausência quase completa do diálogo. Esse estilo deriva de Edgar Allan Poe, que lhe serviu de modelo para a construção de suas narrativas. Os contos de ambos guardam semelhanças: a abertura, escrita como um relato não-ficcional; o uso de adjetivos, que sugerem ou inspiram o horror; e a voz em primeira pessoa, que funciona como indicação do estado mental (crítico) do protagonista, elemento na descrição do personagem (2013, pp. 240-241). Notamos em Lovecraft, portanto, a dependência enfática do dispositivo retórico, que mistura o barroco e o inefável através da descrição plástica e vívida de cenas e eventos. Esse estilo advém da veia gótica do escritor, que não pode ser ignorada. Conforme explica Christoph Grunenberg (1997, p. 195), desde a publicação da obra fundadora do gótico, $O$ Castelo de Otranto (1764), de Horace Walpole, o cenário geográfico e arquitetônico se tornou um dos elementos-chave para a criação de um clima de suspense, antecipação e terror.

O gótico reside naturalmente na paisagem de terror, potencializada pela relação turbulenta entre $o$ personagem humano e o ambiente natural. Na literatura e na arte romântica, o indivíduo e a natureza já não coexistiam em harmonia orgânica, como era proposto pelo ideal pastoral do século XVIII; ao invés disso, homens e mulheres eram arrebatados e aterrorizados pelo temperamento selvagem e incontrolável da natureza (GRUNENBERG, 1997, p. 194). 
Portanto, o gótico é concomitantemente ligado ao "lugar do Mal", o locus horribilis onde monstros residem e coisas estranhas acontecem (GRUNENBERG, 1997, p. 195). Na segunda temporada de Stranger Things, a área rural de Hawkins é transformada em paisagem de horror e funciona como um presságio de que algo está fora do lugar. O apodrecimento das plantações de abóbora pode ser entendido como uma manifestação do Mundo Invertido, dimensão alternativa em rota de colisão com a nossa, com a qual coexiste, o que provoca erupções no tecido da realidade. Uma dessas erupções é descoberta pelo delegado Hopper (2.4 "Will the Wise"). Após escavar um buraco na terra podre e abrir uma passagem entre os dois mundos, decide então explorar as profundezas ocultas, mas se perde nas passagens subterrâneas e acaba sendo capturado por raízes que brotam do solo e o enredam como tentáculos. Nos episódios seguintes, Joyce (Winona Ryder) e Bob (Sean Astin) adentram nas cavernas na intenção de salvar o delegado. É também nas profundezas que Dustin (Gaten Matarazzo), Steve (Joe Keery) e os outros meninos enfrentam as criaturas conhecidas como "Demo-dogs", uma espécie de sabujo alienígena, descendente menos desenvolvido do "Demogorgon" da primeira temporada.

No ensaio "Horror Sobrenatural em Literatura" (1927), Lovecraft aponta que "O medo é a emoção mais forte e mais antiga do ser humano, e o medo do desconhecido é o mais forte e mais antigo dos medos" (LOVECRAFT, 2018, p. 12). Elemento-chave do gótico, a paisagem de terror possibilita a criação da atmosfera e funciona como espacialização ou literalização figurativa da noção de que a fonte do medo existe fora das categorias sociais; logo, é forçosamente desconhecida. Por essa razão, as origens do monstro estão comumente nos lugares desconhecidos pelo mundo humano ou exteriores a ele - continentes perdidos, profundezas do mar ou da terra, espaço sideral; ou em lugares marginais, ocultos ou abandonados (CARROLL, 1999, p. 54). Os arredores de Arkham e o "descampado maldito" abaixo do vale, em "A Cor que caiu do Espaço", bem como a cidade historicamente deteriorada e em ruínas de "A Sombra sobre Innsmouth" (1936) e de outros trabalhos de Lovecraft, surgem como hábitat perfeito para ocorrências monstruosas. Este é o caso da área rural de Hawkins, do ferro-velho em que os jovens combatem a matilha de Demo-dogs, ou do Mundo Invertido, contraparte sombria da pacata cidadezinha americana.

Stranger Things apresenta diversos elementos lovecraftianos, muito dos quais foram elencados por Andy Black (1996) em seu ensaio sobre Lovecraft no cinema: os seres de outra dimensão, os monstros grotescos e os corredores/cavernas labirínticos. Estes últimos, componentes do cenário, fazem clara referência a Alien, de Ridley Scott, considerado o filme lovecraftiano par excellence. As passagens subterrâneas do Mundo Invertido, com suas paredes gosmentas repletas de protuberâncias bulbosas, que ejaculam bílis, lembram o interior da espaçonave abandonada no planeta inóspito, no filme de Scott. Na descrição de Kelly Hurley, as passagens imensas e escuras da espaçonave têm aparência orgânica, semelhante às entranhas de uma baleia. "As paredes internas da nave lembram o interior de 
um corpo, construídas em um material que poderia ser metal, silicone ou osso, revestidas por um padrão repetitivo traçado a partir de um sistema intestinal ou esquelético". A superfície, lamacenta e glutinosa, mais parece o solo de um pântano. Sobre ela estão depositados os ovos alienígenas, "do tamanho de melões inchados, revestidos por uma pele polpuda cinza-rosada" (1995, p. 217). Vale notar que a cabeça de planta carnívora do Demogorgon e de sua prole canina parece ter sido inspirada no design desses ovos.

\section{Entre o sonho e realidade, a loucura}

Deus misericordioso! Que mundo onírico e quimérico teria adentrado? H.P. Lovecraft, A cor que caiu do espaço (2011, p. 46)

Outro tema caro à veia gótica de Lovecraft é a fragilidade da razão humana. Vimos anteriormente que um elemento importante na descrição de seus personagens é o estado mental do protagonista. De acordo com Joshi, "Dagon" (1917) é o primeiro de muitos contos em que o conhecimento em si pode causar perturbação mental. $O$ protagonista é afetado pela existência não somente de uma monstruosidade horrenda, mas de toda uma civilização alienígena que outrora habitava as profundezas do mundo. A questão colocada por esse conto é a fragilidade do nosso estado psicológico. Lovecraft sustenta que a verdade, segundo sua concepção (forças desconhecidas operantes no universo e a inexistência de um Deus para reger o cosmos), pode causar danos irreparáveis àqueles que vão ao seu encontro. Joshi considera "Dagon" uma "proto-ficção-científica" uma vez que o fenômeno descrito não apenas desafia, mas expande as nossas concepções de realidade (2013, pp. 250; 251-2).

Nas histórias de Lovecraft, portanto, o contato com um fenômeno anômalo ou com um conhecimento previamente ignorado costuma levar à insanidade - e, em muitos casos, à morte. Em A cor que caiu do espaço, o narrador fornece uma rica descrição do enlouquecimento da Sra. Gardner, mediante o relato de Ammi Pierce.

Aconteceu em junho, mais ou menos quando a queda do meteoro fez um ano; a pobre mulher vociferava a respeito de coisas indescritíveis que pairavam no ar. Nos delírios, não havia um único substantivo específico - apenas verbos e pronomes. As coisas moviamse, transformavam-se e esvoaçavam, e os ouvidos da mulher captavam o ritmo de impulsos que não eram propriamente sons. Algo fora levado - a sra. Gardner se dizia parasitada por alguma coisa - algo que não devia existir prendia-se ao corpo da mulher - alguém precisava manter aquilo longe - tudo se mexia à 
noite - inclusive as paredes e as janelas. Nahum não a mandou para o hospício do condado e preferiu mantêla em casa enquanto não oferecesse riscos a si mesma e aos outros. Nem quando a expressão da sra. Gardner mudava Nahum esboçava qualquer reação. (...) Em julho, a mulher havia parado de falar e andava apenas de quatro, e antes que o mês acabasse, Nahum teve a bizarra impressão de que ela cintilava no escuro, como, sem dúvida, fazia a vegetação próxima (Lovecraft, 2011, pp. 37-8).

Na segunda temporada de Stranger Things, o pequeno e raquítico Will (Noah Schnapp) passa por um processo de degeneração mental condicionado pelas suas incursões recorrentes e involuntárias no Mundo Invertido; tenebrosas como um pesadelo, tais incursões são a herança maldita dos acontecimentos da primeira temporada. ${ }^{6}$ Em um momento, o menino de doze anos está seguro em casa; numa fração de tempo, o local é dominado por uma atmosfera desolada e assustadora (2.1 "Mad Max"). A porta da frente se abre, revelando uma paisagem exterior devastada, encoberta de muco e formas orgânicas aberrantes. Will se depara com o céu densamente nublado, entrecortado pelos raios escarlates da tempestade elétrica. Uma criatura aracnídea gigantesca emerge à distância, por trás das árvores mortas que cercam o horizonte. A estranha experiência deixa o menino petrificado. No primeiro episódio, ele relata as suas crises para o Dr. Sam Owens (Paul Reiser):

vWILL: Well, my friends were there, and then they just weren't, and I was back there again.

DR. OWENS: In the Upside Down? All right, so what happened next?

WILL: I heard this noise, and so I went outside and it was worse. There was this storm.

DR. OWENS: Okay. So, how did you feel when you saw the storm?

WILL: I felt frozen. (...) Like how you feel when you're scared and you can't breathe or talk or do anything. I felt... I felt this evil, like it was looking at me.

DR. OWENS: It was evil? Well... What do you think the evil wanted?

6 A primeira temporada gira em torno do misterioso desaparecimento de Will, que leva sua mãe, o delegado de polícia de Hawkins e seus amigos a confrontarem forças estranhas para trazê-lo de volta. 
WILL: To kill.

DR. OWENS: To kill you?

Will: Not me. Everyone else.

O diagnóstico feito pelo médico atesta estresse pós-traumático, desordem mental que pode se desenvolver em pessoas expostas a eventos traumáticos; segundo o especialista, a desordem teria aberto as comportas neurológicas e trazido à tona memórias do acontecimento. No segundo episódio (2.2 "Trick or Treat, Freak"), Will é novamente transportado para o Mundo Invertido na noite de Halloween. Depois da perturbadora experiência, tenta explicar a Mike (Finn Wolfhard) as sensações estranhas que afloram como resultado do contato com esse outro mundo, e o amigo sutilmente questiona a sua integridade mental.

WILL: And there was this noise, coming from everywhere. And then I saw something. (...) It was like this huge shadow in the sky. Only, it was alive. And it was coming for me.

MIKE: Is this all real? Or is it like the doctors say, all in your head?

WILL: I don't know, just... Just please, don't tell the others, okay? They won't understand.

MIKE: Eleven would. (...) Sometimes I feel like I still see her. (...) Sometimes I feel like I'm going crazy.

WILL: Me, too.

MIKE: Hey, well, if we're both going crazy, then we'll go crazy together, right?

Mike não precisa se preocupar, pois, seguindo o modelo das narrativas lovecraftianas, o horror está internalizado em Will; é ele quem está propenso a estabelecer contato com uma realidade inacessível aos demais personagens - à exceção de Eleven (Millie Bobby Brown) que, todavia, não encara essa outra dimensão com estranheza, pois parece fazer parte dela. No terceiro episódio (2.3 "The Pollywog"), Will volta a ser transportado para o Mundo Invertido. Ele está na escola quando os corredores subitamente se transformam e a misteriosa sombra começa a persegui-lo. $\mathrm{O}$ menino foge, apenas para cair na versão alternativa de Hawkins, que o aguardava do lado de fora. A gigantesca sombra emerge no campo, tomando a forma de um monstro grotesco cujo corpo parece ser constituído de 
fumaça negra compacta, o que lhe infunde estranha forma aracnídea e cabeça reptiliana. A visão perturbadora é recorrente até esse encontro, no qual o monstro consegue finalmente dominar o menino, penetrando seus orifícios com tentáculos de fumaça negra.

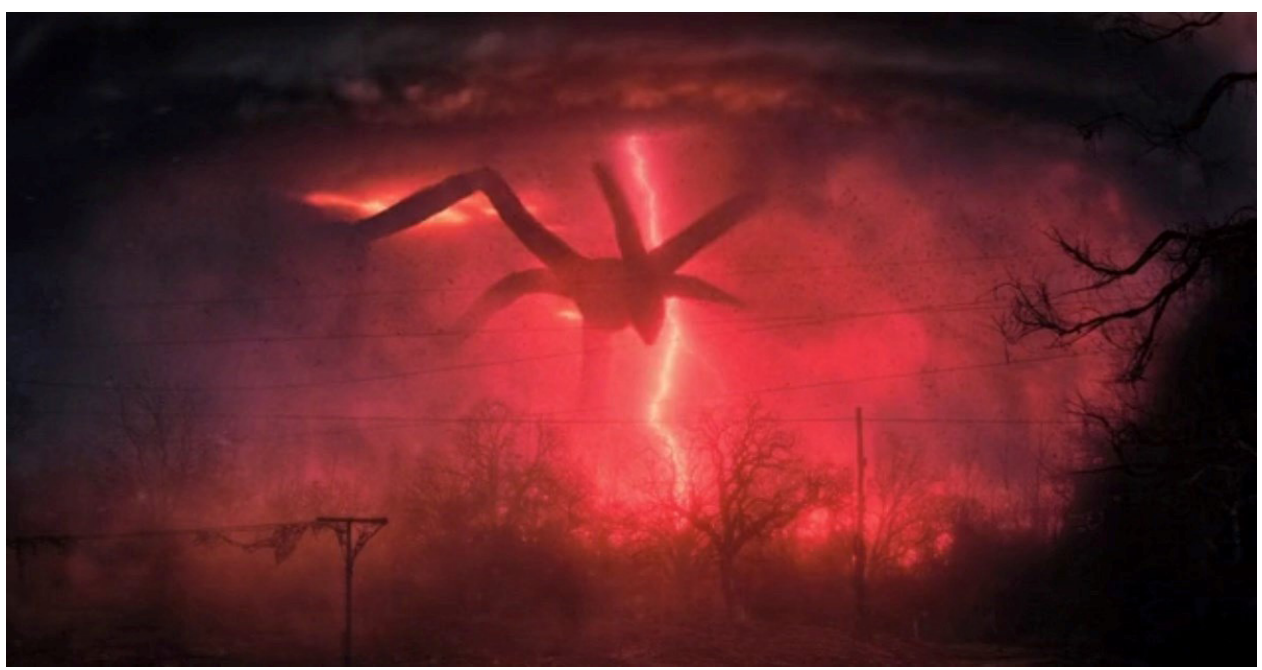

Figura 2 - O misterioso monstro avistado por Will.

Fonte: Netflix.

Will revela a Joyce, sua mãe, ter visto a "Coisa" no campo, mas não sabe o que ela é ou o que quer (2.4 "Will the Wise"). "É quase uma sensação (...) Ele veio até mim e eu tentei. Tentei fazer com que fosse embora. Mas ele me pegou (...) Senti isso em todos os lugares. Todos os lugares. E ainda sinto. Só quero que isso acabe". A mente de Will se conecta involuntariamente a "lembranças do fundo da mente", mas essas lembranças não pertencem a ele e estão embaralhadas. $\mathrm{O}$ menino as define como "memórias do Agora" e tenta descrevê-las: "É como se estivessem crescendo e se espalhando, matando". O domínio da criatura também causa mudanças físicas, provocando o estado de letargia e colapsos nervosos. Ainda no episódio quatro, Joyce mede a temperatura de Will, que está frio e sentese como se ainda não tivesse acordado. A "Coisa" parece gostar do frio. Will sabe disso intuitivamente, pois não se comunica diretamente com o ser. Simplesmente sabe das coisas, o que revela uma conexão entre a mente superior do parasita e a mente frágil do hospedeiro, o que lhes permite trocar informações telepaticamente. O menino dá sinais de ter sido dominado pela criatura quando ela começa a falar através dele. No episódio seguinte (2.5 “Dig Dug”), Will tem outra conversa franca com Mike. 
WILL: It's like... It's like I feel what the shadow monster's feeling. See what he's seeing.

MIKE: Like in the Upside Down?

WILL: Some of him is there. But some of him is here, too.

MIKE: Here, like, in this house?

WILL: In this house and... in me. It's like... It's like he is reaching into Hawkins more and more. And the more he spreads, the more connected to him I feel.

MIKE: And the more you see these now-memories.

WILL: At first I just felt it in the back of my head. I didn't even know it was there. It's like when you have a dream and you can't remember it unless you think really hard. I was like that. But now it's like... Now I remember. I remember all the time.

No segundo episódio (2.2 "Trick or Treat, Freak"), a fronteira entre sonho e realidade é questionada. Joyce, a sempre determinada mãe de Will, explica a Hopper que o filho não trata as crises como se fossem um pesadelo, mas como se fossem reais. O próprio Will, por sua vez, revela a Mike sentir-se preso entre os dois planos, o "real" e a outra dimensão conhecida como Mundo Invertido. Esse foi um recurso comumente utilizado por Lovecraft. "Sonhos são coisas estranhas, perigosas e esquisitas", ${ }^{7}$ afirma o escritor inglês de fantasia Neil Gaiman na introdução a The Dream Cycle of H.P. Lovecraft: Dreams of Terror and Death (1995). O "Ciclo dos Sonhos", como ficou conhecido, engloba uma série de contos escritos por Lovecraft entre 1918 e 1932, que tratam de incursões às "Dreamlands", dimensões alternativas que só podem ser acessadas através dos sonhos. O primeiro deles é "Polaris" (1918), no qual um homem confunde a realidade e o mundo de sonho. Em "The Dream-Quest of Unknown Kadath" (1926) é descrito um "mundo inferior", abaixo das Dreamlands, iluminado pela misteriosa fosforescência conhecida como "fogo da morte" e habitado por diversos horrores. De certa forma, uma espécie de Mundo Invertido alheio ao nosso.

\section{Analogia interdimensional: o Devorador de Mentes}

No primeiro episódio, Will é transportado para o mundo de sonho conhecido como Mundo Invertido. Lá, tem a visão de uma gigantesca criatura aracnídea que surge à distância, caminhando como uma sombra, com pernas

7 Livre tradução de: "Dreams are strange things, dangerous and odd". 
tentaculares, sobre uma versão alternativa e distópica de Hawkins. Somos apresentados pela primeira vez a esse que parece ser o grande vilão da segunda temporada. No quarto episódio (2.4 "Will the Wise"), o delegado Hopper define o monstro como "Coisa das Sombras", porém nada se sabe sobre ele. Na verdade, o que quer que seja é quase indescritível, assim como a maioria dos monstros das histórias de Lovecraft, comumente denominados de "coisas" por serem inomináveis. As entidades alienígenas em $A$ cor que caiu do espaço são um bom exemplo: "A cor (...) era quase impossível de descrever; e foi apenas por analogia que puderam designá-la como tal" (Lovecraft, 2011, p. 28). De acordo com Joshi, é precisamente a impossibilidade de definir a natureza - seja ela física ou psicológica - dessas entidades (ou mesmo se elas são criaturas vivas como entendemos) que produz a sensação de horror inominável (2013, p. 673). No penúltimo episódio (2.8 "The Mind Flayer"), Mike, Dustin (Gaten Matarazzo) e Lucas (Caleb McLaughlin) chegam a importantes conclusões. Segundo Dustin, o "Monstro das Sombras" possui "mente de colmeia"; é uma "consciência coletiva" ou um "superorganismo" que controla todas as coisas, "como o Devorador de Mentes".

A analogia proposta por Dustin no intuito de compreender a "Coisa" estabelece relação com uma monstruosidade cósmica tipicamente lovecraftiana, o que pode ser depreendido a partir da descrição feita pelo personagem. Conforme Dustin explica para os seus companheiros, o Devorador de Mentes seria o monstro de uma dimensão desconhecida, tão antigo que não se lembra do seu verdadeiro lar. Além de escravizar raças de outras dimensões, tomando seus cérebros com "poderes psiônicos" desenvolvidos, seu objetivo último seria "nos conquistar", pois "ele acredita ser uma raça mestre"; "ele considera outras raças, como nós, como inferiores". Logo, "quer se propagar e tomar outras dimensões". Dustin enfatiza a gravidade da situação, ao concluir que "Estamos falando da destruição do nosso mundo como o conhecemos".

De acordo com os irmãos Matt e Ross Duffer, em entrevista concedida à Entertainment Weekly e na mesa-redonda de O Universo de Stranger Things (Beyond Stranger Things, 2017), ${ }^{8}$ como a segunda temporada é maior e mais cinematográfica, decidiram criar um novo vilão. Em vez de um ser que age instintivamente, como o Demogorgon da primeira temporada - confessamente inspirado no horror sugerido de Tubarão (Jaws, dir. Steven Spielberg, 1975) —, os criadores pensaram em um ser de outro mundo capaz de agir conscientemente, uma mente coletiva conectando todas as coisas. Esse conceito levou à criação do Devorador de Mentes, uma ameaça que tem planos, objetivos e pensamentos, ainda que o espectador não vá necessariamente compreendê-los. Temos aqui uma abordagem lovecraftiana de horror, como destacam os irmãos Duffer. É o horror cósmico, algo que se manifesta de uma outra dimensão e cujas intenções são obscuras, pois estão além da compreensão humana.

8 Roda de bate-papo com os diretores e atores da segunda temporada de Stranger Things. 


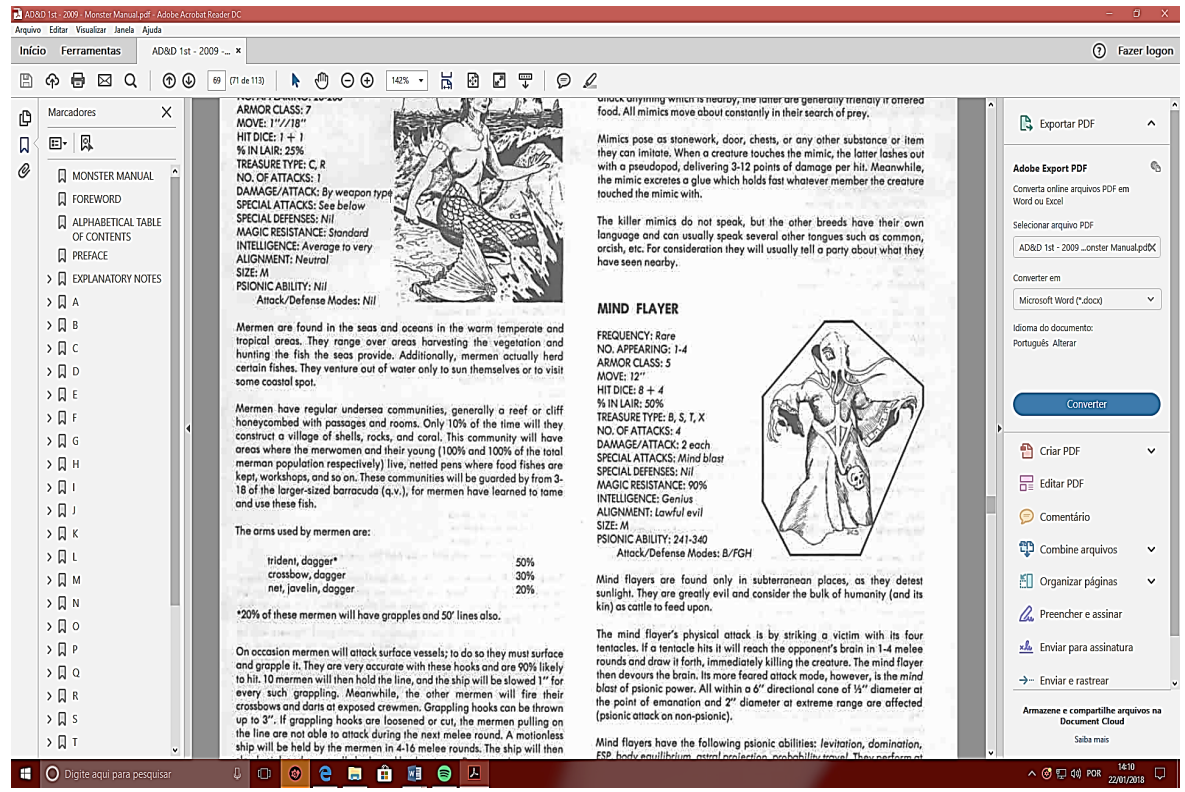

Figura 3 - Imagem do "Devorador de Mentes" conforme aparece no Monster Manual fo Dungeons \& Dragons, mostrada em Stranger Things (2.8 'The Mind Flayer').

Fonte: GYGAX, 1979.

A mitologia criada por Lovecraft pressupõe a existência de um panteão de seres ocultos conhecidos como Os Grandes Anciões, que governaram a Terra em tempos remotos, antes do advento da humanidade. ${ }^{9}$ Nas histórias de Lovecraft, essas entidades alienígenas, amorfas e não-humanas foram banidas do mundo e existem em outras dimensões, onde aguardam impacientes para retornar, e o seu retorno culminará inevitavelmente na aniquilação de nossa espécie. Os desafortunados humanos que cruzam o seu caminho descobrem, para o seu horror, um universo muito mais sombrio e hostil. Os Mitos de Cthulhu têm como marco fundacional o conto "O Chamado de Cthulhu" (1926), com germes em textos anteriores de sua carreira. A sua influência é de longo alcance e tem inspirado autores como Stephen King, Clive Barker, John Carpenter, Stuart Gordon, Guillermo del Toro e os irmãos Duffer.

Assim como o do próprio Demogorgon, o nome desse novo vilão surgiu para os criadores da série enquanto pesquisavam Dungeons \& Dragons (D\&D), RPG de fantasia criado por Gary Gygax e Dave Arneson em 1974. O Devorador de

\footnotetext{
9 As principais entidades dessa mitologia são Nyarlathotep, a "alma" do caos; Azathoth, o deus cego e idiota que habita no centro do caos; Yog-Sothoth, vice-regente de Azathoth, o Portal para o Vazio Exterior; Cthulhu, Senhor dos Profundos; e Shub-Niggurath, o Grande Bode Preto da Floresta com Mil Jovens. Os nomes desses deuses alienígenas foram criados pelo próprio Lovecraft com base na influência de diversas culturas e na junção de palavras de diversas tradições.
} 
Mentes faz parte do bestiário e da mitologia de D\&D desde o fim dos anos 1970. Apareceu originalmente na primeira edição do Monster Manual for Advanced D\&D (1977), obra de referência na qual é descrito como um ser raro, de inteligência altamente desenvolvida, dotado de poderes "psiônicas" e outras habilidades, como levitação, dominação e projeção astral, que habita lugares subterrâneos, pois detesta a luz do sol. Na verdade, não se trata de um único ser, mas de uma espécie cujos membros "são muito maus e consideram a maior parte da humanidade (e sua prole) como gado para se alimentar" (GYGAX, 1979, p. 60). Atacam suas vítimas com seus quatro tentáculos e, caso atinjam o alvo, o cérebro será afetado e ela morrerá instantaneamente.

Esses monstros falam apenas sua própria linguagem arcana e várias outras línguas estranhas - supostamente aquelas das terríveis raças das coisas que habitam regiões do mundo subterrâneo para além daquelas em que a humanidade jamais ousou se aventurar. Também há rumores de que esses monstros têm uma cidade em algum lugar embaixo da terra (GYGAX, 1979, p. 60).

Na segunda edição do Monster Manual, ${ }^{10}$ o Devorador de Mentes é descrito como uma criatura maligna e temida que se alimenta do cérebro de qualquer criatura que encontra e, usando poderes místicos, escraviza ou destrói seus inimigos. Ele detesta a luz do sol e a evita sempre que possível, por isso vive em Underdark. Este mundo, um dos muitos cenários de D\&D, é constituído por uma vasta rede subterrânea de cavernas interconectadas, que formam um mundo inferior (GYGAX, 1995, p. 251). Dentro do sistema de alinhamento dos personagens de $\mathrm{D} \& \mathrm{D}$, a tendência do Devorador de Mentes é vil ("lawful evil"), própria das criaturas que seguem um código de conduta rígido, fazem uso da sociedade e de suas leis para benefício próprio e tencionam ampliar seus poderes sobre outros seres dentro da hierarquia do universo. Ele tem pele lilás, recoberta com gosma brilhante; a cabeça lembra um polvo, com olhos brancos e quatro tentáculos ao redor da boca, orifício redondo repleto de dentes semelhante ao de uma lampreia. Notadamente pela fisionomia alienígena e pelos tentáculos gosmentos, é inegável a semelhança entre o Devorador de Mentes e Cthulhu - monstro humanoide gigante com um polvo no lugar da cabeça. Não obstante, Gygax parece ter encontrado a inspiração para esse personagem na capa de The Burrowers Beneath (1974), romance do escritor inglês Brian Lumley. O nome de Lumley ficou conhecido no círculo dos Mitos de Cthulhu, ao qual aderiu nos anos 1970, escrevendo diversas 
histórias que emulam o estilo de Lovecraft. Os "Cefálidas" do RPG Magic: The Gathering também são claramente derivativos, e possuem tanto a aparência como os poderes do Devorador de Mentes de D\&D.

\section{Considerações finais}

A princípio, a influência de Lovecraft sobre Stranger Things parece indireta, já que a sua obra inspirou muito da literatura e do cinema dos anos de 1980, de autores como Stephen King, Ridley Scott e John Carpenter, cujos trabalhos de horror e ficção científica inspiraram a segunda temporada da série. No entanto, saltam à vista traços marcantes de uma das principais histórias de Lovecraft, $A$ Cor que Caiu do Espaço, e elementos marcantes de sua composição ficcional mais geral, com destaque para os Mitos de Cthulhu. Primeiro, o monstro conhecido como Devorador de Mentes que emerge de outra dimensão com sua inteligência superior, seus propósitos desconhecidos e aparente desinteresse para com a sorte dos humanos, reduzindo-os à sua insignificância cósmica. Segundo, a área rural de Hawkins, transformada em paisagem de horror, amplificando o suspense e criando uma atmosfera essencialmente lovecraftiana, com raízes no naturalismo do gótico. Outros pontos afastados da cidade, como as cavernas orgânicas do Mundo Invertido, também abrigam abominações e ocorrências monstruosas, que subvertem as leis da Natureza. Terceiro, Will é profundamente afetado pelas suas incursões nessa dimensão sombria; não apenas pela monstruosidade horrenda que se anuncia, mas pela existência de toda uma civilização que habita as profundezas do mundo. A fragilidade da razão humana é posta em evidência. Seguindo o modelo das narrativas lovecraftianas, o horror está internalizado em Will, capaz de estabelecer contato, ainda que involuntário, com uma realidade inacessível aos demais. Mediante esse contato, a fronteira entre sonho e realidade se borra, tal qual nas histórias do Ciclo dos Sonhos de Lovecraft. Em determinado momento, Hopper pergunta a Joyce o que ela quer fazer e para onde quer levar Will para que ele possa ser tratado. E ela responde: "tem aquele cara em Boston, que supostamente...", mas é interrompida pelo delegado. É curioso pensar que a possível resposta para os estranhos acontecimentos estaria em Boston, Massachussets, na antiga Nova Inglaterra de Lovecraft, locus horribilis de sua composição ficcional.

\section{Referências}

BLACK, A. Crawling celluloid chaos - H.P. Lovecraft in cinema. NecronomiconThe Journal of Horror and Erotic Cinema. Book 1. London, UK: Creation Books, 1996.

CARROLL, N. A filosofia do horror ou paradoxos do coração. Campinas, SP: Papirus, 1999. 
GRUNENBERG, C. (ed.). Gothic: transmutations of horror in late twentieth century art. Cambridge, Massachusetts: MIT Press, 1997.

GYGAX, G. Monster Manual for Advanced Dungeons \& Dragons. 4 ed. Lake Geneva, MI: TSR Games, 1979. Jovem, 1995. . Livro dos Monstros para Advanced Dungeons \& Dragons. São Paulo: Abril HURLEY, K. “Reading like an alien: posthuman identity in Ridley Scott's 'Alien' and David Cronenberg's 'Rabid”'. In: HALBERSTAM, Judith; LIVINGSTON, Ira (eds.). Posthuman bodies. Bloomington: Indiana University Press, 1995.

JOSHI, S.T. I am Providence: The Life and Times of H.P. Lovecraft. New York, NY: Hippocampus Press, 2013.

KELAHAN, M. H.P. Lovecraft on the silver screen. In: H.P Lovecraft goes to the movies. New York: Fall River Press, 2011.

LOVECRAFT, H.P. A cor que caiu do espaço. Trad. Guilherme da Silva Braga. São Paulo: Hedra, 2011.

. "Horror sobrenatural em literatura". In: Grandes contos. 2 ed. São Paulo: Martins Fontes, 2018, pp. 1099-1174.

. The Dream Cycle of H.P. Lovecraft: Dreams of Terror and Death. New York, NY: Ballantine Books, 1995.

MIGLIORE, A.; STRYSIK, J. Lurker in the Lobby: A Guide to the Cinema of H.P. Lovecraft. 2nd ed. Portland, CA: Night Shade Books, 2006.

OATES, J.C. The King of Weird. In: The New York Review of Books, 1996.

Disponível em: http://www.nybooks.com/articles/1996/10/31/the-king-of-weird/. Acesso em: 22/01/2018.

REIS FILHO, Lúcio. Pasticho ao molho pardo (à moda dos anos 80): Ingredientes e Modo de Preparo de Turbo Kid (2015). Passagens, Ceará, v. 8, n. 2, 2017. Disponível em: www.periodicos.ufc.br/passagens/article/view/30962. Acesso em: 15 jan. 2018.

ROTHMAN, J. The Old, American Horror Behind "Stranger Things". In: The New Yorker, 2016. Disponível em: https://www.newyorker.com/books/joshuarothman/the-infinite-nostalgia-of-stranger-things. Acesso em: 20/01/2018.

STACK, T. Stranger Things 2: Behind the sequel's big, bad 'shadow monster'. In: Entertainment Weekly, 2017. Disponível em: http://ew.com/tv/2017/09/28/ stranger-things-2-new-monster/. Acesso: 21/01/2018. 
Something to recall the secrets of the strange days: H.P. Lovecraft's worldview in Stranger Things

\begin{abstract}
Strange things happen in Hawkins, Indiana. In 1983, supernatural phenomena begin to disturb the quiet Midwestern town after a governmental agency surreptitiously opens a gateway to another dimension, releasing the horrors that live within. This is the premise of "Stranger Things" (Netflix, 201617), American sci-fi/horror web television series. However, we know from which dimension these horrors emerge: from Stephen King's novels, Spielberg's films, and Dungeons \& Dragons' campaigns. In spite of the most obvious channels of intertextuality, we will observe the most relevant influence for the atmosphere of horror in Season 2: the oeuvre of H.P. Lovecraft, remarkably "The Colour out of Space" and the Cthulhu Mythos. The Lovecraftian approach, confirmed by the series' creators, turns Hawkins into a landscape of terror; leads one of the protagonists to the brink of madness; and, behind the curtains of reality, casts the deadly shadow of an elder abomination.
\end{abstract}

\title{
Keywords
}

Stranger Things. H.P. Lovecraft. The Colour out of Space. Cthulhu Mythos. 